УДК 621.396 .9

DOI: https://doi.org/10.26642/ten-2020-2(86)-117-121

Ж.Ш. Жантаев, д.ф.-м.н., проф. директор ДТОО «Институт ионосферы»,

$A O$ «Национальный центр космических исследований и технологий» $P К$

А.Ф. Дубина, к.т.н., доц.

А.В. Андреев, к.т.н., доц.

Г.Шарипова, магистрант

Государственный университет «Житомирская политехника»

\title{
Использование интерферометрической космической радиолокационной съемки высокого разрешения для мониторинга деформации сооружений
}

\begin{abstract}
B последние годы наиболее эффективными $и$ актуальными являются методики $c$ использованием дистаничонного зондирования Земли с применением спутниковой радарной интерферометрии (метод интерферометрии с использованием радаров с синтезированной апертурой (PCA)). Как известно, по результатам многопроходных космических радарных съемок одной и той же территории, выполненных с одинаковыми параметрами и геометрией съемки, можно сделать оиенку смещения земной поверхности, в том числе различных зданий и сооружений. Используя метод РСА интерферометрии, можно регистрировать смещения природных $u$ техногенных объектов на любой выбранной территории с точностью до 1 мм. Для решения этой задачи спутниковый мониторинг ведется в непрерывном режиме. Город Нур-Султан республики Казахстан располагается в местах слабого грунта с близко расположенным к поверхности водоносным горизонтом. Как показывает практика, строительство высотных зданий со временем вызывает их просадку и деформачии. Были выбраны строения «Транспорт Тауэр» и «Байтерек» для исследования просадочных зон. Исходными данными для последующей интерферометрической обработки служили космические радарные снимки данных объектов и прилегающих территорий, сделанные со спутников COSMO-SkyMed 1-4 (е-GEOS, Италия) в течении трех лет. В результате интерферометрической обработки радарных космических снимков в разные годы и сезоны были выявлены смещения и деформации земной поверхности и сооружений. Это может быть полезно при планировании и строительстве высотных зданий и их эксплуатации.
\end{abstract}

Ключевые слова: дистаничионное зондирование Земли; интерферометрическая обработка; радар с синтезированной апертурой.

Постановка проблемы. В настоящее время широко известны созданные общедоступные данные цифровой карты высот поверхности земли SRTM-3 (плановая дискретизация 90 м), полученные в ходе выполнения проекта Shuttle Radar Topographic Mission в 1999 г. [1]. Появление в последние годы космических РСА нового поколения высокого (8-10 м) и сверхвысокого (1-3 м) разрешения, таких, как ALOS PALSAR, RADARSAT-2, TerraSAR-X, CosmoSkyMed 1-4, открыли новые возможности для построения детальных цифровых моделей рельефа (ЦМР).

Технологии интерферометрической обработки данных космической радиолокационной съемки, базирующиеся на алгоритмах интерферометрической обработки, реализованы в специализированных программных комплексах обработки данных Д33, таких как SARscape, PSP-IfSAR (e-GEOS, Италия), IMAGINE Radar Mapping, Photomod Radar, RATools. Вместе с тем на пути практического применения данных двухпроходной интеферометрической съемки для получения детальной ЦММ приходится преодолевать ряд существенных проблем. К их числу, в первую очередь, относятся пространственная декорреляция данных и проблемы «развертки фазы» при обработке радиолокационных данных сверхвысокого разрешения, содержащих большое количество областей «разрыва» фазы (при съемке городской территории - зданий и сооружений).

Столица республики Казахстан г. Нур-Султан располагается в местах слабого грунта с близко расположенным к поверхности водоносным горизонтом. Как показывает практика, строительство высотных зданий со временем вызывает их просадку [2] и деформации [3, 4]. Одними из грандиозных и показательных объектов для определения параметров этих процессов являются строения «Транспорт Тауэр» и «Байтерек». Эти сооружения были сданы в эксплуатацию в 2002 г. Административнотехнологический комплекс «Транспорт Тауэр» составляет 32 этажа и имеет высоту 155,15 м. Высота сооружения «Байтерек» составляет 97 м, а с шаром, венчающим конструкцию, - 105 м. Здания имеют много таких устойчивых отражателей радарного сигнала, как углы между стеной и землей, стеной и крышей, углы балконов и т. д. (рис. 1), поэтому установка специальных отражателей радарного сигнала не требуется.

В этой статье проводится измерение динамики проседания и деформации строений «Транспорт Тауэр» и «Байтерек» г. Нур-Султан с применением метода интерферометрии с использованием РСА. 


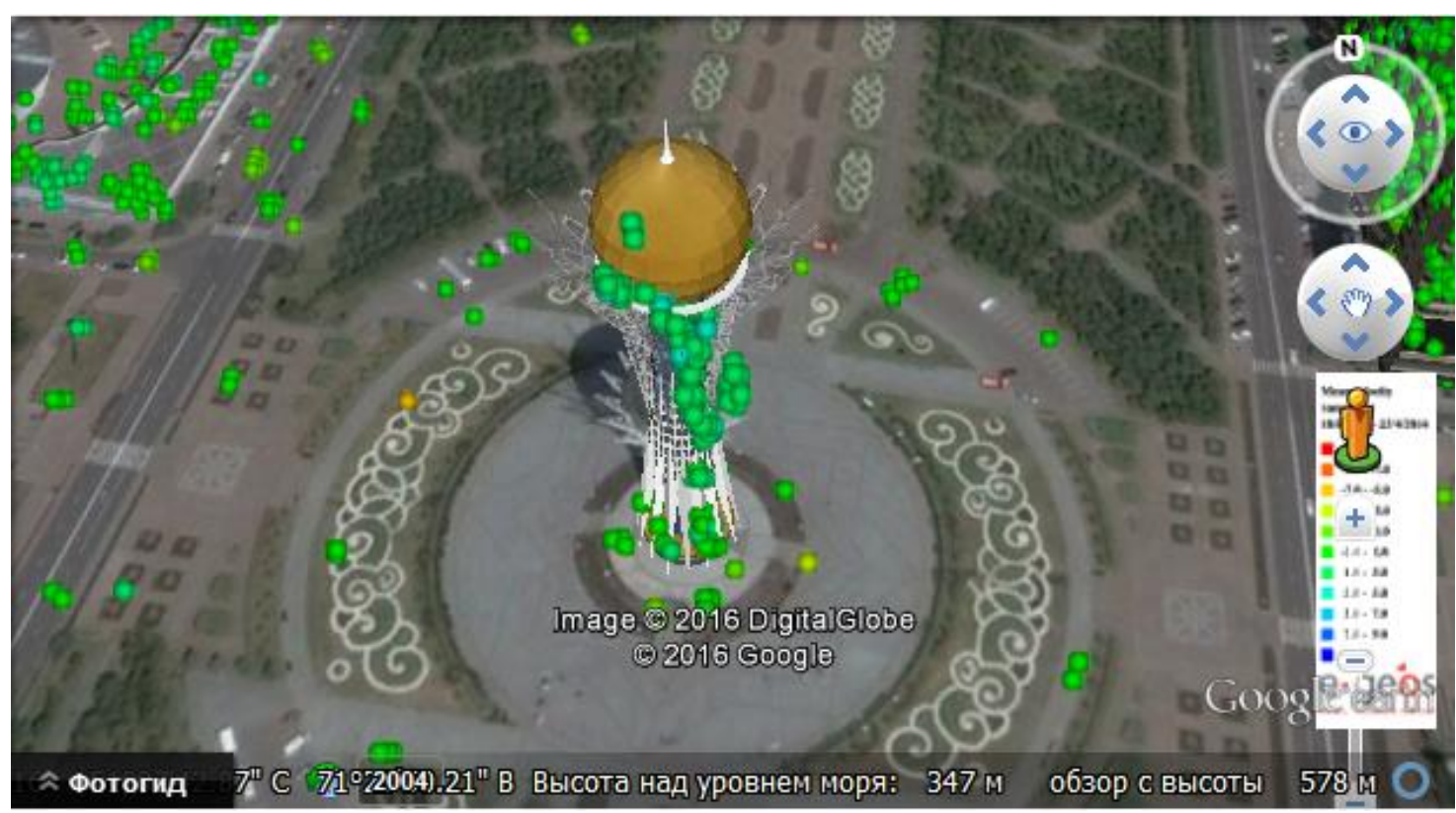

Рис. 1. Устойчивые отражатели радарного сигнала, выявленные на сооружении «Байтерек»

Анализ последних исследований и публикаций. Принципы определения координат объекта на поверхности Земли путем цифрового некогерентного синтезирования апертуры антенны и оценка точности высоты объектов рассмотрены, например, в [5, 6]. Однако до настоящего времени картографирование движения точек на земной поверхности должным образом не развивалось. Сравнительно немногочисленные карты, основывающиеся на результатах интерферометрической обработки, имеют иллюстративный характер, не приведены к единой картографической основе, представляют информацию в чрезмерно обобщенном виде [7]. Отмеченные недостатки приводят к тому, что эти карты могут выполнять функцию визуализации результатов наблюдений, но не могут быть инструментом исследования изменений геодинамических параметров объектов на земной поверхности. В то же время значительная и постоянно возрастающая информация о движении точек на земной поверхности, обширные геологические и геофизические данные требуют создания системы картографического обеспечения геодинамических исследований, которая позволила бы выявлять пространственно-временные особенности и изменения регистрируемых геодинамических параметров. В полной мере это может быть обеспечено только с использованием ГИС-технологий, что позволит проводить геодинамический мониторинг, обновлять базы данных, систематизировать и визуализировать полученные результаты в виде различных тематических карт, выявлять взаимодействие различных явлений в геодинамике и геодезии, связанных с тектоникой литосферных плит.

Изложение основного материала. Технологическая схема построения ЦММ при интерферометрической обработке данных космических РСА содержит следующие этапы: синтезирование пары комплексных радиолокационных изображений (РЛИ); взаимопривязку изображений одной и той же области поверхности; формирование интерферограммы путем поэлементного комплексного перемножения двух РЛИ; компенсацию фазового набега от опорной поверхности; фильтрацию фазового шума; устранение фазовой неоднозначности; построение цифровой модели местности [8]. На этапе фильтрации производится построение коэффициента когерентности обрабатываемого изображения, который представляет собой отношение между когерентной и некогерентной суммами отсчётов первого и второго изображений [9]. Участки, где коэффициент когерентности меньше заданного порога (обычно $0,25)$, в дальнейшем исключаются из построения ЦМР. Развёртывание фазы устраняет скачки на $2 \pi$ [10].

Для проведения геодинамического мониторинга, базирующегося на алгоритмах интерферометрической обработки, служили космические радарные снимки территории г. Нур-Султан и прилегающих территорий, сделанные со спутников COSMO-SkyMed 1-4 в течении трех лет. Интерферометрическая обработка снимков PCA с целью выявления смещений и деформаций земной поверхности и сооружений выполнялась в программных комплексах PSP-IfSAR и свободно распространяемой программой Google Earth. Дешифрирование и интерпретация данных многопроходных космических радарных съемок выполнялись с получением на выходе моделей смещений исследуемых объектов в миллиметрах по состоянию на каждую дату съемки (за поверхность, относительно которой рассчитывались смещения, была принята поверхность, отражающая радарный сигнал на момент первой по порядку съемки). Интерферометрическая обработка данных многопроходных космических радарных съемок выполнялась без наземных контрольных точек и без использования данных наземных наблюдений. 
В качестве опорного рельефа при интерферометрической обработке радарных данных использовалась глобальная общедоступная цифровая модель рельефа. На рисунке 2 белым квадратом показана окресность территории комплекса «Байтерек», подлежащая анализу.

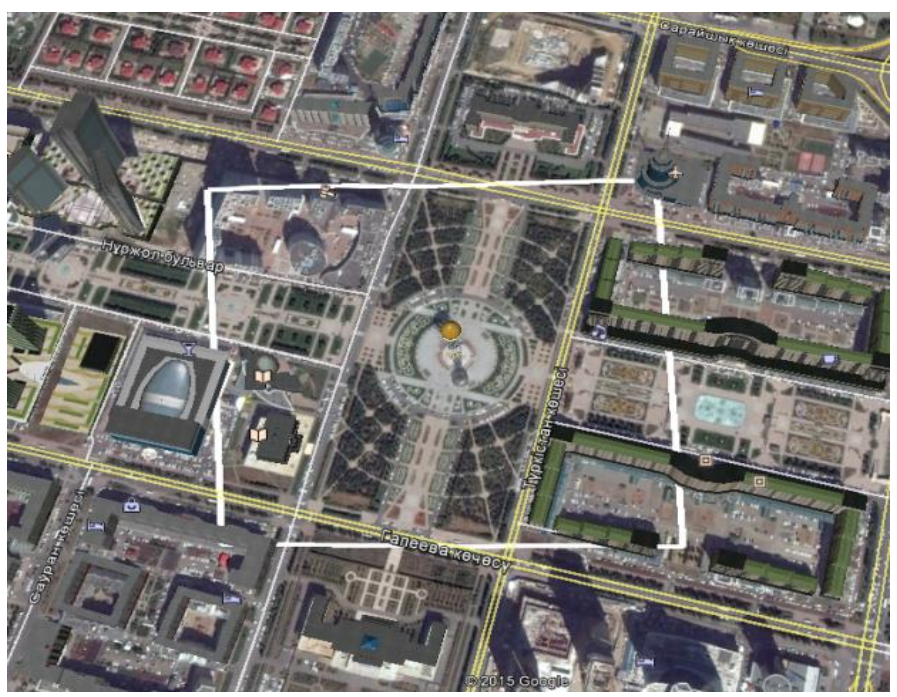

Рис. 2. 3D-модель геомеханического состояния системы «грунт-сооружение»

Результаты комплексной обработки радарных данных движения земной поверхности анализируемых территорий с помощью программного пакета Sarscape (Envi) в виде карт распределения вертикальных смещений представлены на рисунках 3-6. Результаты анализа скорости смещения (мм/год) за три года зданий «Транспорт Тауэр» и «Байтерек» и их окружений представлены на рисунке 3.

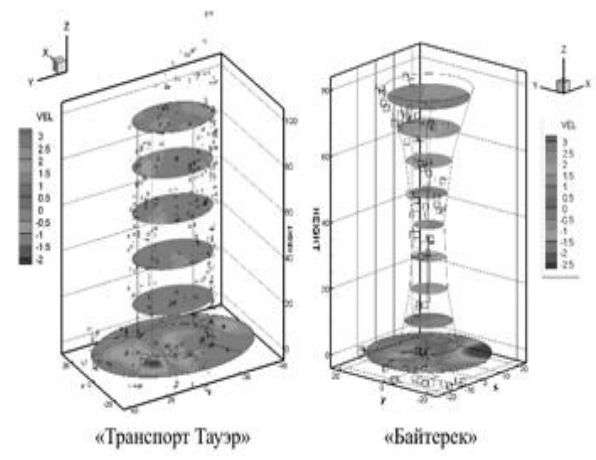

Рис. 3. Средние скорости смещений зданий «Транспорт Тауэр» и «Байтерек»

Наложение на 3D-модель сооружений полученных значений скоростей смещений отражателей радарного сигнала позволило выявить просадочные зоны сооружений «Байтерек» и «Транспорт Тауэр». Отражатели покрашены по величине смещений: изменение тона участка соответствует поднятию или оседанию, расширению металлической конструкции или сжатию. В северо-восточной окрестности «Байтерек» рассматривается сильное оседание, это связано со входом в сооружение. Анализ скоростей смещения сооружения «Байтерек» в осенний период представлен на рисунке 4.
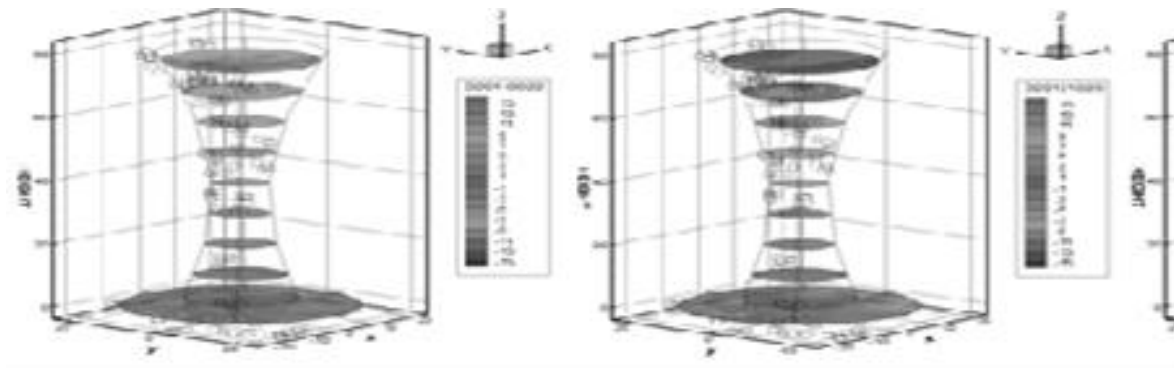

Рис. 4. Скорости смещения строения «Байтерек» мм/год за три года (осенний период) 
Нур-Султан расположен в зоне с резко-континентальным климатом, поэтому в осенний период рассматривается просадка в самом здании «Байтерек» и окрестности. Это связано с влиянием физических процессов и природных явлений.

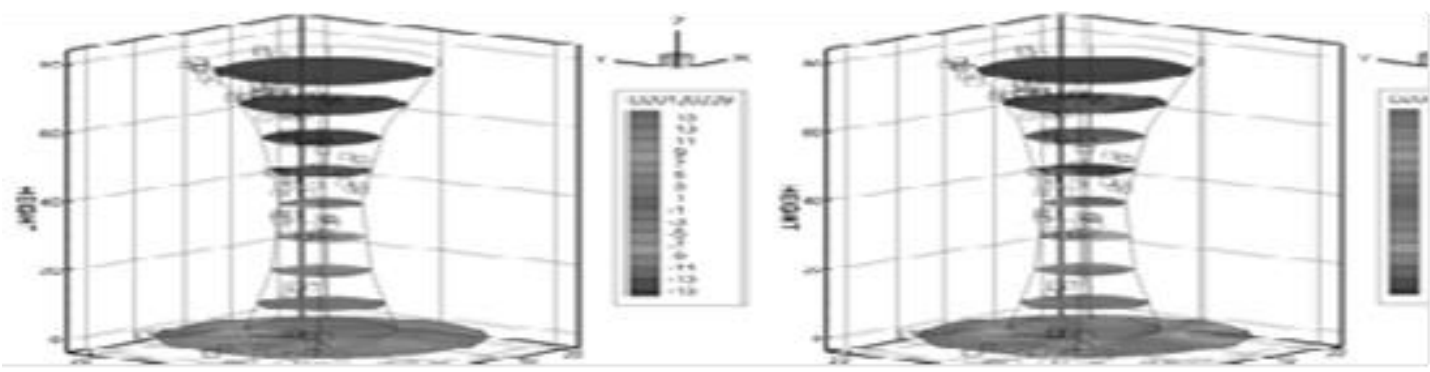

Рис. 5. Скорости смещеения строения «Байтерек» за три года (зимний период), мм/год

В зимний период, связанный с сильными снегопадами и дождями, металлическое сооружение (рис 5) демонстрирует аномальное сжатие. Анализ снимков за летний и весенний сезоны (рис. 6) показывает, что здание «Байтерек» и его окрестность поднимается. Это объясняется прямым попаданием солнечных лучей на сооружение и резким изменением погодных условий.

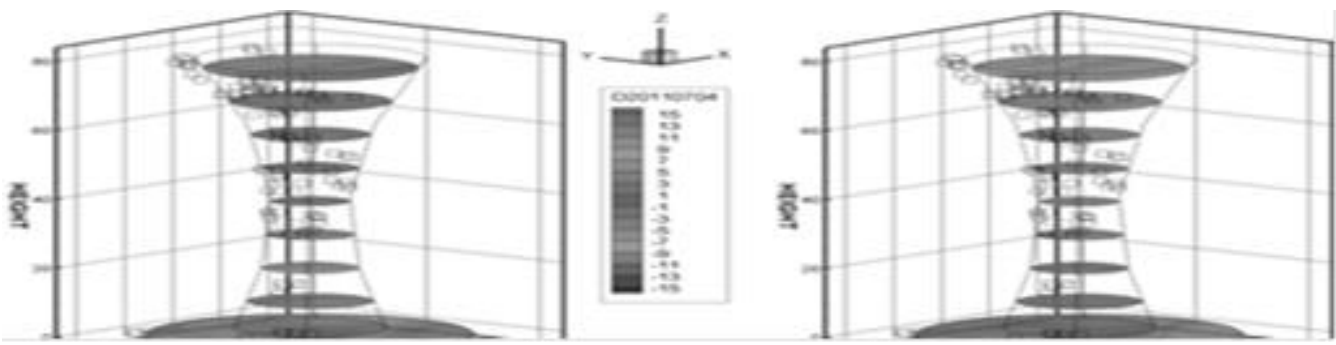

Рис. 6. Скорость смещчения строения «Байтерек» за два года (весенний и летний периоды), мм/год

Выводы. Проведена обработка и анализ высокоточных спутниковых радарных снимков высокого разрешения при помощи метода интерферометрии с использованием РСА. По полученным данным построены и интерполированы 3D-модели сооружений «Транспорт Тауэр» и «Байтерек», показаны годовые и сезонные смещения. В ходе строительства и после его завершения происходят осадочные явления. Процесс просадки должен идти равномерно и постепенно прекратиться. Если осадка неравномерная, могут возникнуть различные деформации, в том числе и крен здания. Сооружения высотой более 15 м могут деформироваться из-за ветра или неравномерного нагрева стен солнцем. Контроль за этими процессами очень важен в ходе эксплуатации зданий. Особенно важен мониторинг деформации таких сооружений. Важно зарегистрировать деформацию на ранней стадии, когда ее устранение будет наименее затратным. Это направление в области обработки данных Д3З позволяет решать задачи своевременного мониторинга смещений и деформаций земной поверхности и сооружений с целью предотвращения чрезвычайных ситуаций с применением методики интерферометрической обработки серий спутниковых радарных изображений. Этот метод полностью соответствует таким критериям. Предлагаемые способы анализа и интерпретации представляются достаточно обоснованными. Интерполированные 3D-модели сооружений могут быть полезны для мониторинга и учета смещений и деформаций земной поверхности и сооружений городов.

\section{Список использованной литературы:}

1. Nikolakopoulos K.G. SRTM vs ASTER elevation products. Comparison for two regions in Crete, Greece / K.G. Nikolakopoulos, E.K. Kamaratakis, N.Chrysoulakis // International Journal of Remote Sensing. - London : Taylor \& Francis, 2006. - Vol. 27, № 21.

2. Eray Can Effects of mining subsidence on mhard coal region in Turkey / Eray Can, Senol Kuscu, Murat Emre Kartal // Springer-Verlag. - 2011.

3. Байков В. Математическая геология / В.Байков, Н.Бакиров, А.Яковлев. - 1-е изд. - Ижевск : Институт компьютерных исследований, 2012. - Т. 1. - С. 227.

4. Камеварова Г.Г. Методика определения предельно допустимых деформаций панельных зданий, эксплуатируемых на подработанной территории / Г.Г. Кашеварова, М.П. Сон // Вестник ЮУрГу. Серия : Строительство и архитектура.

5. Андреєв О.В. Алгоритм пасивного синтезування апертури антени з рухомої платформи : зб. наукових праць / О.В. Андреєв, П.П. Топольницький // Житомир : ЖВІДУТ, 2014. - № 9. - С. 85-92. 
6. Визначення точності виміру висот об'єктів при автоматичній обробці стереознімків / О.Ф. Дубина, O.B. Андреєв, T.M. Нікітчук, О.М. Свінцицька // Вісник НТУУ «Київський політехнічний інститут». Серія : Радіотехніка. Радіоапаратобудування. - 2020. - Вип. 82. - С. 67-73.

7. Радиолокационные системы землеобзора космического базирования / В.С. Верба, Л.Б. Неронский, И.Г. Осипов, В.Э. Турук ; под ред. В.С. Вербы. - М. : Радиотехника, 2010. - 680 с.

8. Коберниченко В.Г. Анализ алгоритмов интерферометрической обработки данных космической радиолокационной съемки / В.Г. Коберниченко, А.В. Сосновский // Физика и технические приложения волновых процессов. - Самара : Изд-во Самарского государственного университета, 2010. - № 3.

9. Synthetic aperture radar interferometry / R.M. Goldstein, Fuk K.Li et al. // Proceedings of the IEEE. - 2000. - Vol. 88, № 3. - P. 333-381.

10. Hanssen Ramon F. Radar Interferometry / Ramon F. Hanssen. - Kluwer Academic Publishers, 2002. - 308 p.

\section{References:}

1. Nikolakopoulos, K.G., Kamaratakis, E.K. and Chrysoulakis, N. (2006), «SRTM vs ASTER elevation products. Comparison for two regions in Crete, Greece», International Journal of Remote Sensing, Taylor \& Francis, London, Vol. 27, No. 21.

2. Can, Eray, Kuscu, Senol and Emre Kartal, Murat (2011), «Effects of mining subsidence on mhard coal region in Turkey», Springer-Verlag.

3. Baikov, V., Bakirov, N. and Yakovlev, A. (2012), Matematicheskaya geologiya, 1st ed., Institut komp'yuternykh issledovanii, Izhevsk, Vol. 1, pp. 227.

4. Kashevarova, G.G. and Son, M.P., «Metodika opredeleniya predel'no dopustimykh deformatsii panel'nykh zdanii, ekspluatiruemykh na podrabotannoi territorii», Vestnik YuUrGu, Seriya Stroitel'stvo i arkhitektura.

5. Andrejev, O.V. and Topol'nyc'kyj, P.P. (2014), Algorytm pasyvnogo syntezuvannja apertury anteny $z$ ruhomoi' platform, zb. naukovyh prac', ZhVIDUT, Zhytomyr, No. 9, pp. 85-92.

6. Dubyna, O.F., Andrejev, O.V., Nikitchuk, T.M. and Svincyc'ka, O.M. (2020), «Vyznachennja tochnosti vymiru vysot ob'jektiv pry avtomatychnij obrobci stereoznimkiv», Visnyk NTUU «Kyi'vs'kyj politehnichnyj instytut», Serija Radiotehnika. Radioaparatobuduvannja, Issue 82, pp. 67-73.

7. Verba, V.S., Neronskii, L.B., Osipov, I.G. and Turuk, V.E. (2010), Radiolokatsionnye sistemy zemleobzora kosmicheskogo bazirovaniya., in Verba, V.S. (ed.), Radiotekhnika, M., 680 p.

8. Kobernichenko, V.G. and Sosnovskii, A.V. (2010), «Analiz algoritmov interferometricheskoi obrabotki dannykh kosmicheskoi radiolokatsionnoi s'emki», Fizika i tekhnicheskie prilozheniya volnovykh protsessov, Izd-vo Samarskogo gosudarstvennogo universiteta, Samara, No. 3.

9. Goldstein, R.M., K.Li, Fuk et al. (2000), «Synthetic aperture radar interferometry», Proceedings of the IEEE, Vol. 88, No. 3, pp. 333-381.

10. Hanssen, Ramon F. (2002), Radar Interferometry, Kluwer Academic Publishers, 308 p.

Жантаев Жумабек Шабденамович - доктор физико-математических наук, профессор, членкорреспондент НАН Республики Казахстан, директор ДТОО «Институт ионосферы», АО «Национальный центр космических исследований и технологий».

Научные интересы:

- GPS-мониторинг региональных движений земной коры;

- обработка радиолокационных космических снимков, полученных с РСА;

- математическое моделирование сейсмотектонических процессов в земной коре.

Дубина Александр Федорович - кандидат технических наук, доцент, доцент кафедры биомедицинской инженерии и телекоммуникаций Государственного университета «Житомирская политехника».

Научные интересы:

- обработка сигналов в радиотехнических системах;

- цифровая обработка изображений.

E-mail: Fedorovich_daf@ukr.net.

Андреев Александр Владимирович - кандидат технических наук, доцент, доцент кафедры биомедицинской инженерии и телекоммуникаций Государственного университета «Житомирская политехника».

Научные интересы:

- $\quad$ моделирование и обработка информации в радиотехнических системах.

E-mail: Oleks.andreyev@gmail.com.

Шарипова Гульнар - магистрант гр. ТРм-19-2 специальности «Телекоммуникации и радиотехника» Государственного университета «Житомирская политехника».

Научные интересы:

- цифровая обработка изображений;

- обработка радиолокационных космических снимков, полученных с РСА.

Статья поступила в редакцию 31.07.2020. 